\title{
Simulation of large PV energy facilities with SAM HCPV and PV detailed models
}

\author{
Alberto Boretti ${ }^{1, *}$, Jamal Nayfeh ${ }^{1}$, Wael Al-Kouz ${ }^{1}$ \\ ${ }^{1}$ Mechanical Engineering Department, College of Engineering, Prince Mohammad Bin Fahd University, Saudi Arabia
}

\begin{abstract}
Here we compare the measured energy production of the solar photovoltaic (PV) energy facilities of Solar Star and Desert Sunlight with the values computed in National Renewable Energy Laboratory (NREL) System Advisor Model (SAM), by using the SAM database for the typical weather, and the different models available, the high concentration photovoltaic (HCPV) model, as well as the PV detailed model. Both models are semi-empirical. The HCPV is the most sophisticated model, permitting the specification of a much larger number of parameters. The detailed PV model is less flexible. The comparison shows that SAM computes winter and summer energy productions that are much closer than what is shown by the experiments, dramatically underrating the seasonal variability. This is due to a solar resource for direct normal irradiance during winter and summer that is much closer to what is shown by other databases, such as Weather Spark, for their incident shortwave solar energy inclusive of seasonal variations, the elevation of the Sun above the horizon, and absorption by clouds and other atmospheric constituents. The contribution highlights the issue of the mostly missing validation of renewable energy tools, in needs of proper high-frequency simultaneous weather and plant data, both at the system and the level of the individual components, before their use for performance estimations.
\end{abstract}

\section{Introduction}

The renewable energy sector and its applications are of great interest to many researchers in the last few decades. These include but are not limited to desalination, power generation and Heating, Ventilation, and Air Conditioning (HVAC). Moreover, many researchers studied the effects of climatic conditions such as temperature, wind speed, and dust on the performance of renewable energy systems as well as the trends of electricity demands and its susceptibility to the ambient air temperature towards sustainable electricity generation [1-4]

Solar photovoltaic $(\mathrm{PV})$ is scaling up rapidly, with capacity dramatically increasing in recent years [5]. On an annual basis, renewable power grew worldwide by $14.5 \%$. The solar generation grew by 30 mtoe (megatonnes of oil equivalent), only slightly less than the increase in the wind ( $32 \mathrm{mtoe}$ ), and provided more than $40 \%$ of renewables growth. By country, China was the largest contributor to renewables growth (32 mtoe), surpassing growth in the entire Organisation for Economic Co-operation and Development (OECD) (26 mtoe). Hydroelectric generation increased by $3.1 \%$. Nuclear generation also rose by $2.4 \%$, with China (10 mtoe) contributing almost three-quarters of global growth, and Japan (5 mtoe) had the second-largest increase. Within the US, solar generation is growing significantly especially in California, where there are presently 32 plants of registered capacity of $100 \mathrm{MW}$ and above, see Table 1 . The average capacity factor of solar thermal is 0.25 , while the average capacity factor of solar PV is a much larger 0.30 . Because of increasing uptake and the phasing out of back-up conventional power plants producing energy on demand rather than when the resource solar or wind is available, there is the necessity to study the variability of the capacity factor with a high frequency of every minute or less, with the help of reliable data for what concerns the resource and the power plant, as well as to develop reliable models. Here we propose a validation exercise of the National Renewable Energy Laboratory (NREL) System Advisor Model (SAM) software and the supporting resource database for the case of the two largest PV solar energy facilities of California, Sola Star, and Desert Sunlight.

Solar Star (Table 2) is a $579-\mathrm{MW}_{\mathrm{AC}} \mathrm{PV}$ power station near Rosamond, California. When completed in 2015 , it was the world's largest solar energy facility in terms of installed capacity, using 1.7 million solar panels spread over $13 \mathrm{~km}^{2}$. Compared to other PV plants of similar size, Solar Star uses a smaller number (1.7 million) of large form-factor, high-wattage, highefficiency, higher cost crystalline silicon modules, mounted on single-axis trackers. In contrast to Solar Star, Desert Sunlight (Table 3) a $550 \mathrm{MW}_{\mathrm{AC}} \mathrm{PV}$ power station close to Desert Center, California, uses 8.8 million of smaller form-factor, lower wattage, efficiency,

Corresponding author: a.a.boretti@gmail.com 
and cost thin-film CdTe PV modules, mounted on fixedtilt arrays and spread over a larger land area of $16 \mathrm{~km}^{2}$.

Table 1. Solar power plants in California. Energy production data for the year 2018. Data from [6].

\begin{tabular}{|c|c|c|c|}
\hline Plant Name & $\begin{array}{l}\text { Power } \\
M W\end{array}$ & $\begin{array}{l}\text { Energy } \\
M W h\end{array}$ & $\begin{array}{l}\text { Capacity } \\
\text { Factor }\end{array}$ \\
\hline \multicolumn{4}{|c|}{ Solar Thermal } \\
\hline \multirow{5}{*}{$\begin{array}{r}\text { Genesis } \\
\text { Ivanpah I } \\
\text { Ivanpah II } \\
\text { Ivanpah III } \\
\text { Mojave }\end{array}$} & 250 & 623,189 & 0.28 \\
\hline & 126 & 242,425 & 0.22 \\
\hline & 133 & 277,055 & 0.24 \\
\hline & 133 & 276,327 & 0.24 \\
\hline & 250 & 604,777 & 0.28 \\
\hline \multicolumn{4}{|c|}{ Solar Photovoltaic } \\
\hline \multirow{5}{*}{$\begin{array}{r}\text { Antelope Valley } 1 \\
\text { Blythe Solar } 1 \\
\text { Blythe Solar II } \\
\text { California Flats N } \\
\text { California Valley }\end{array}$} & 250 & 606,235 & 0.28 \\
\hline & 110 & 298,847 & 0.31 \\
\hline & 125 & 345,083 & 0.32 \\
\hline & 130 & 361,793 & 0.32 \\
\hline & 250 & 674,796 & 0.31 \\
\hline \multirow{2}{*}{$\begin{array}{r}\text { Campo Verde } \\
\text { Catalina Solar PI,II }\end{array}$} & 147.2 & 326,508 & 0.25 \\
\hline & 110 & 265,818 & 0.28 \\
\hline & 174 & 458,800 & 0.30 \\
\hline Desert Stateline & 299 & 667,167 & 0.25 \\
\hline Desert Sunlight 250 & 250 & 619,867 & 0.28 \\
\hline \multirow{2}{*}{$\begin{array}{r}\text { Desert Sunlight } 300 \\
\text { Garland Solar }\end{array}$} & 300 & 724,937 & 0.28 \\
\hline & 205.1 & 601,730 & 0.33 \\
\hline Great Valley Solar & 200 & 540,441 & 0.31 \\
\hline \multirow{2}{*}{$\begin{array}{r}\text { Henrietta Solar } \\
\text { Imperial Solar South }\end{array}$} & 102 & 251,373 & 0.28 \\
\hline & 128.9 & 274,473 & 0.24 \\
\hline \multirow{2}{*}{$\begin{array}{r}\text { Imperial Solar West } \\
\text { Mt. Signal } 3\end{array}$} & 148.7 & 377,263 & 0.29 \\
\hline & 252.3 & 137,635 & \\
\hline \multirow{2}{*}{$\begin{array}{r}\text { Panoche Valley Solar } \\
\text { Quinto Solar PV }\end{array}$} & 240 & 9,999 & \\
\hline & 108 & 285,687 & 0.30 \\
\hline \multirow{2}{*}{$\begin{array}{r}R E \text { Astoria } \\
\text { Silver Ridge Mount Signal }\end{array}$} & 100 & 287,883 & 0.33 \\
\hline & 200 & 510,086 & 0.29 \\
\hline \multirow{2}{*}{$\begin{array}{r}\text { Solar Star I } \\
\text { Solar Star II }\end{array}$} & 318 & 906,705 & 0.33 \\
\hline & 279 & 790,128 & 0.32 \\
\hline Springbok Solar 1 & 105 & 298,337 & 0.32 \\
\hline Springbok Solar 2 & 155 & 407,457 & 0.30 \\
\hline Topaz Solar LLC & 550 & $1,335,720$ & 0.28 \\
\hline Tranquillity LLC & 205.3 & 501,751 & 0.28 \\
\hline
\end{tabular}

Table 2 - Data of Solar Star

\begin{tabular}{l|c|}
\hline Location & Rosamond, California \\
\hline $\begin{array}{l}\text { Latitude } \\
\text { Longitude }\end{array}$ & $34^{\circ} 49^{\prime} 50^{\prime \prime} \mathrm{N}$ \\
Year Completed & $118^{\circ} 23^{\prime} 53^{\prime \prime} \mathrm{W}$ \\
Type & 2014 \\
Site area & Flat-panel PV \\
& $13 \mathrm{~km}^{2}$ \\
\hline & Solar Star 1 \\
\hline Nameplate Capacity & $398 \mathrm{MW}_{\mathrm{dc}} 314 \mathrm{MW}_{\mathrm{ac}}$ \\
Capacity factor & $32.95 \%(2018)$ \\
& Solar Star 2 \\
\hline & $350 \mathrm{MW}$ \\
Nameplate Capacity & $33.91 \%(2018)$ \\
Capacity factor & $\mathrm{MW}_{\mathrm{ac}}$ \\
\hline
\end{tabular}

Table 3 - Data of Desert Sunlight

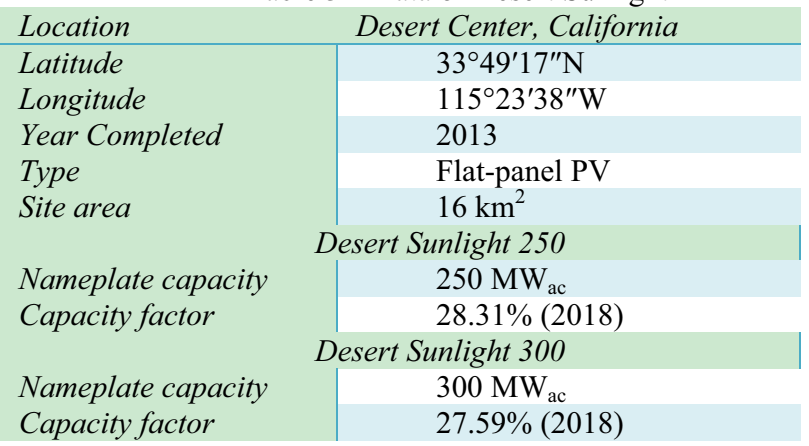

\section{Materials and methods}

Electricity production data of PV plants in the United States have been obtained through the collection of public domain information from the United States Energy Information Administration [7]. The data of [7] are available every month as a net generation in MWh. From the net installed capacity (power) $\mathrm{P}$ in MW, monthly capacity factors $\varepsilon$ are computed by diving the monthly electricity production by the product of capacity and number of hours in a month.

Simulations are then performed by using SAM [8]. The high concentration PV (HCPV) model represents a solar PV energy facility as an array of modules with one or more inverters. SAM uses a multi-junction cell's efficiency curve and a set of loss factors, as discussed in [9]. The efficiency curve is a linear interpolation of the table of power conversion efficiencies as a function of direct normal irradiance. The model uses an air mass modifier polynomial to approximate spectral effects on the performance of the module. The loss factors account for the optical lens, alignment error, tracker error, wind flutter, and other CPV-specific losses. Spectral effects are accounted for through air mass modifier coefficients. Multi-junction cell efficiency is prescribed based on experience. The cell's efficiency is prescribed at each of up to five plane-of-array (POA) beam irradiance values and specify the reference value for capacity calculations. The inverter model is the empirical Sandia inverter model [10], [11].

Spécification of the system requires a choice of an inverter, a CPV module, and an array. SAM then assumes that HCPV modules are mounted on 2-axis trackers, and calculates tracking power consumption based on the specified tracking power. The model is empirically-based. Despite conceptually different, the HCPV may serve the purpose to represent Solar Star or Desert Sunlight, by tuning, providing data is available to calibrate the many constants. Simulations are also performed with the PV detailed module. In this case, the model parameters are less. it is necessary to select a module, an inverter, and a system design. The PV module calculates the DC electrical output of a single module based on the design parameters and the incident solar radiation (plane-of-array irradiance) calculated from the weather file. The different inverter models calculate the DC to AC conversion efficiency. All these models are empirical. The system design sizes the PV system and chooses the tracking options, no tracking, 1 axis, or 2 axes [8], [9], [10].

\section{Results}

The experimental results of Solar Star and Desert Sunlight were previously analyzed in [12]. In 2017, Solar Star had a capacity factor of $33.0 \%$. In 2016, Solar Star had a capacity factor of $28.5 \%$. In 2015, the capacity factor was $31.9 \%$. In 2016, Desert Sunlight had a capacity factor of $27.9 \%$. In 2015 , the capacity factor was $26.7 \%$. No data were available for 2017 in [12]. 
Fig. 1 and 2 present the experimental results for the two facilities, as well as the results of SAM computations for the typical year with data downloaded from SAM. In the SAM simulations, we use the same models for Solar Star and Desert Sunlight. This may overrate the performances of Desert Sunlight, which is on average 5 percentage points less. We use the HCPV module with two-axis tracking as well as the PV detailed model with no tracking, and 1 axis or 2 axes tracking. The major advantage of HCPV is the opportunity to easily change the overall efficiency.

While the curve of capacity factors in the HCPV model can be shifted up and down by changing the model parameters such as the cell efficiency, there is a significant inconsistency between the computational and the experimental results for the energy production. The computational results show a much smaller seasonal variation. This reduced seasonal variability is proper for both the HCPV and PV detailed models.
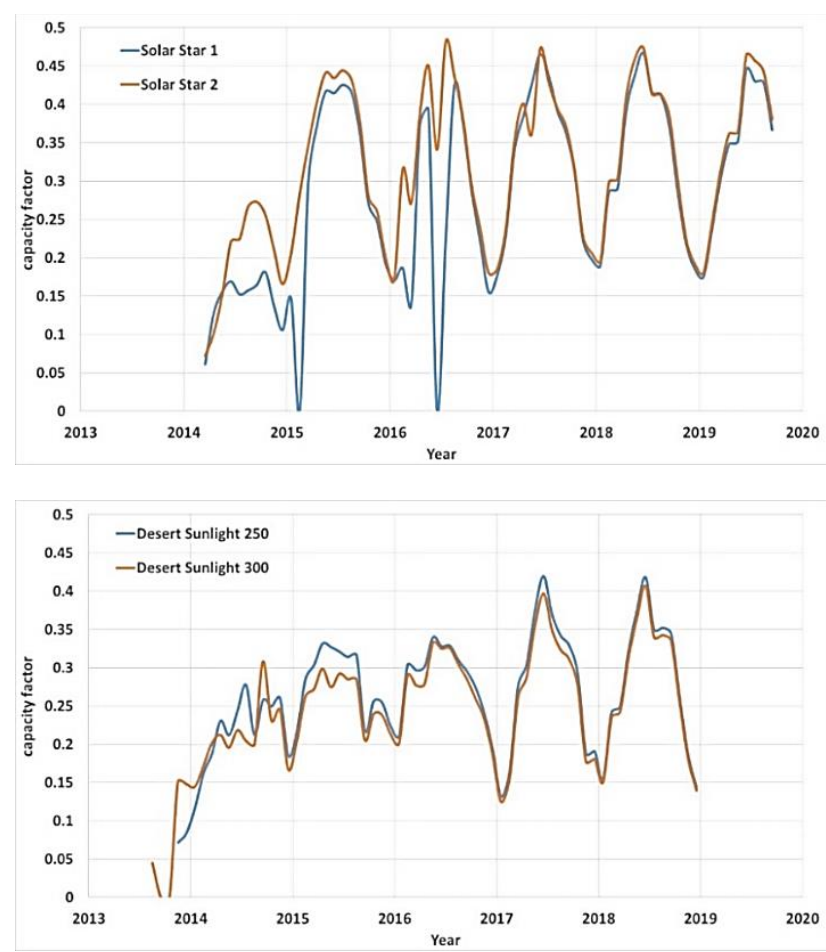

Fig. 1. Solar Star (top) and Desert Sunlight solar (bottom) energy facilities, measured capacity factors since completion.

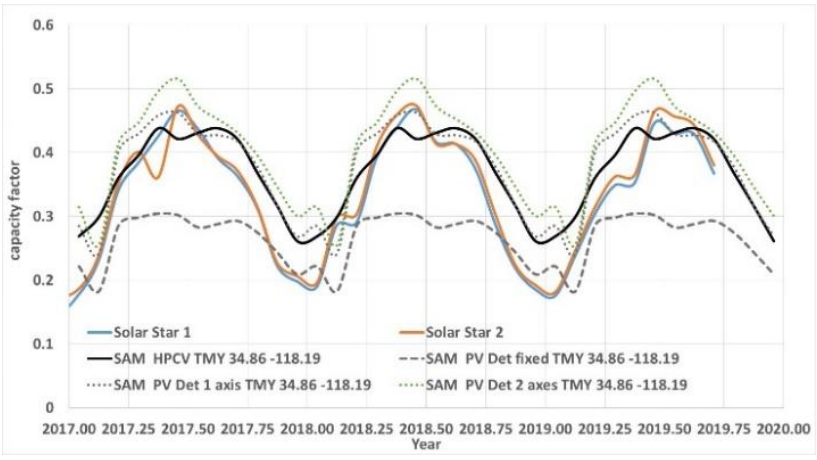

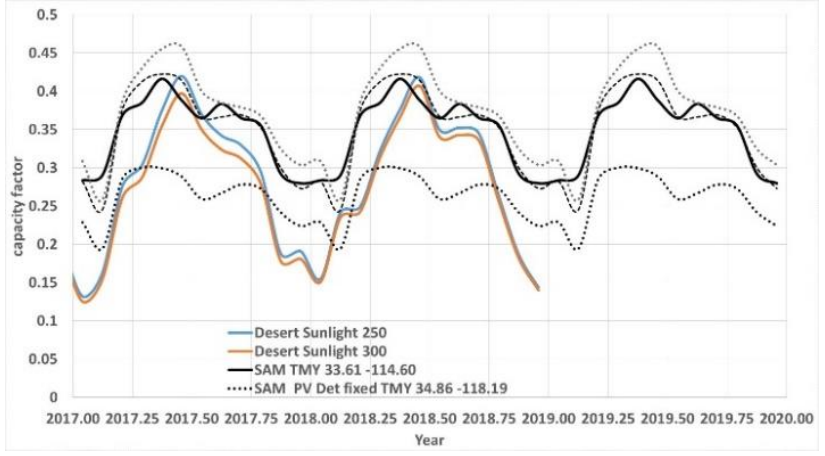

Fig. 2. Solar Star (top) and Desert Sunlight solar (bottom) solar energy facilities measured capacity factors over the last 3 years and computed capacity factors for the typical year. Both the HPPV and PV detailed model results are shown.

What we may notice, apart from the annual average capacity factor that experimentally is higher for the most sophisticated design of Solar Star, is the much larger difference between winter minimum and summer maximum capacity factors in the experiments vs. the models. This is marginally a problem of the model, that is, however, optimistic especially for Desert Sunlight, but a problem of the resource. The summer/winter results are very close to each other. Thus, Fig. 3 presents a comparison of the input irradiance to SAM and the solar resource plus clouds coverage obtained by an alternative source, weather spark [13].

In Solar Star, the ratio between the beam irradiance in June and December is 1.844 . The ratio between the input irradiance is the same. The ratio in between the energy produced in June and December in the models is less, 1.562 in the HPPV because June has the lowest ratio in between energy produced and input irradiance, 0.173 , while in December this ratio is 0.204 .
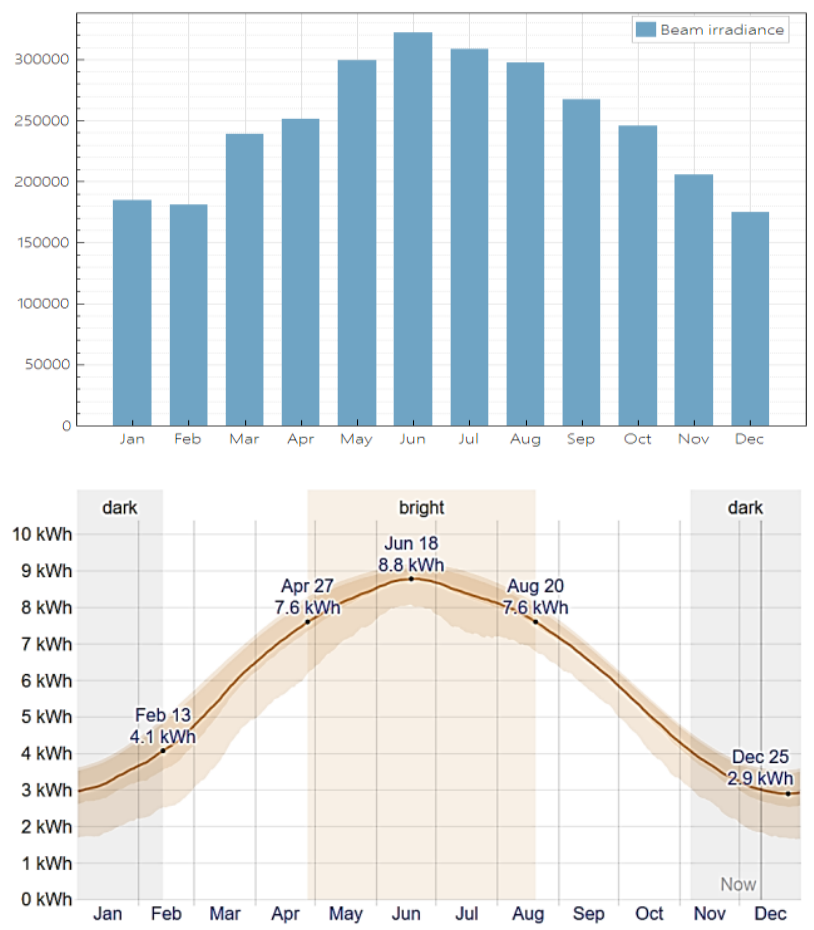

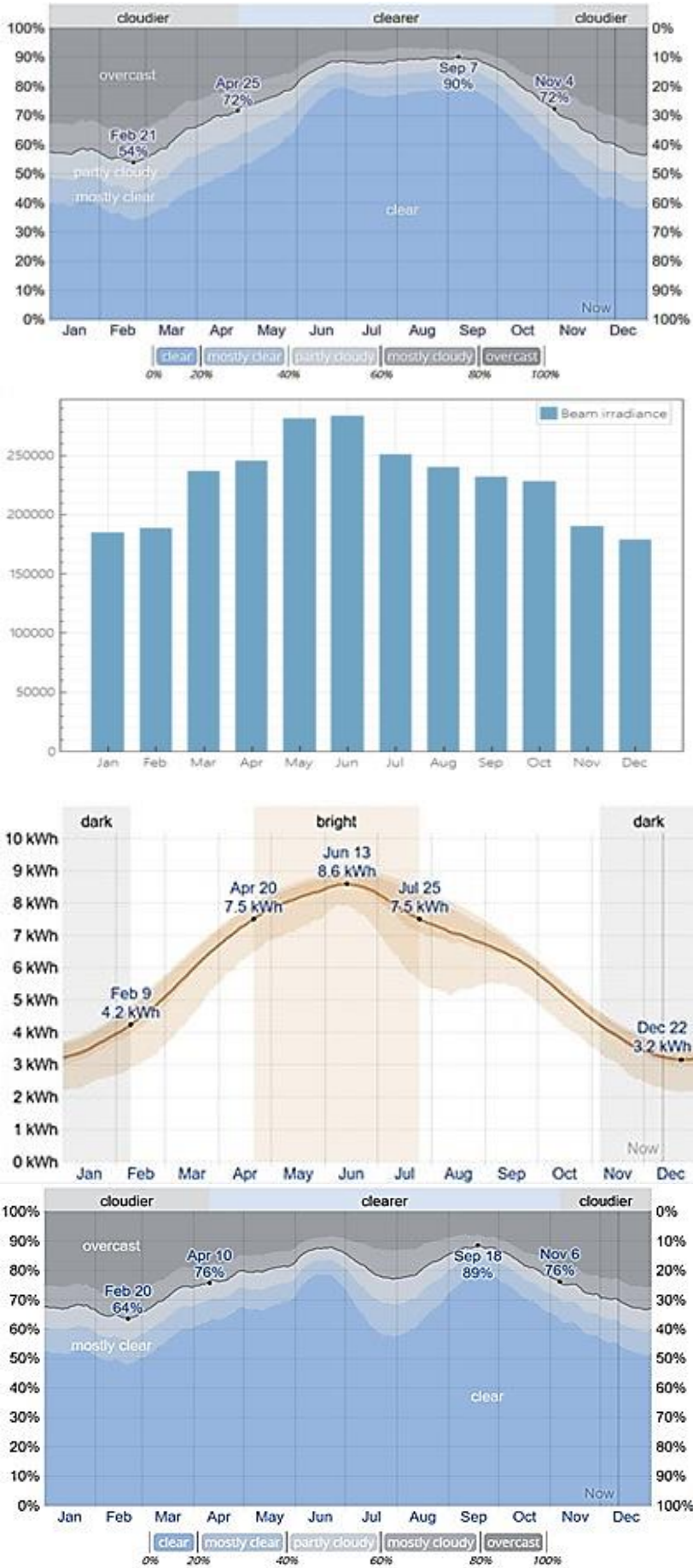

Fig. 3. Comparison of SAM input irradiance and weather spark solar irradiance and cloud coverage for Solar Star (top) and Desert Sunlight (bottom).

If we consider the independent irradiation data, from weather spark [13], the ratio between the average daily incident shortwave solar energy in June and December is about 2.8. June to September is then the period of clearer skies, with very few clouds. December has much larger coverage.

The reason why SAM underrate the differences between summer and winter energy production is simply that SAM has in input an overrated irradiance for the winter compared with the irradiance for the summer. From the measured electricity, the ratio of capacity factors of June and December is $2.524(0.467 / 0.185)$ for
Solar Star 1, and it is $2.468(0.474 / 0.192)$ for Solar Star 2 , not that far from the weather spark data [13], but very far from the SAM resource database.

The very close ratio of energy produced during the summer and the winter is shown also by the simulations for Blythe, CA. From the measured electricity, the ratio of capacity factors of June and December is 2.909 $(0.418 / 0.144)$ for Desert Sunlight 1 , and it is 2.909 $(0.407 / 0.140)$ for Desert Sunlight 2, not that far from the weather spark data [13], where the ratio between the average daily incident shortwave solar energy in June and December is about 2.6. The ratio of the beam irradiance in the SAM weather file is only 1.54. This again explains most of the differences between experiments and simulations in Fig.2. Apart from the typical year that is not the specific year, there is certainly one issue with the source of irradiance data.

The total daily incident shortwave solar energy reaching the surface of the ground over a wide area, proposed in Weather Spark, takes into full account the seasonal variations in the length of the day, the elevation of the Sun above the horizon, and the absorption by clouds and other atmospheric constituents. This shortwave radiation includes visible light and ultraviolet radiation. Unfortunately, this result is only available as a curve of daily values, and not hourly as needed in the TMY file. Hence, the result of the SAM simulation is simply corrected by taking the monthly input irradiances a fraction of the June monthly input irradiance taken as the ratio of the monthly average daily incident shortwave solar energy of the specific month and the June month from Fig.3. The ratio of the AC energy and the input irradiance for every specific month is taken unaltered. Fig. 4 presents the result of the corrected simulations with drastically improved accuracy.

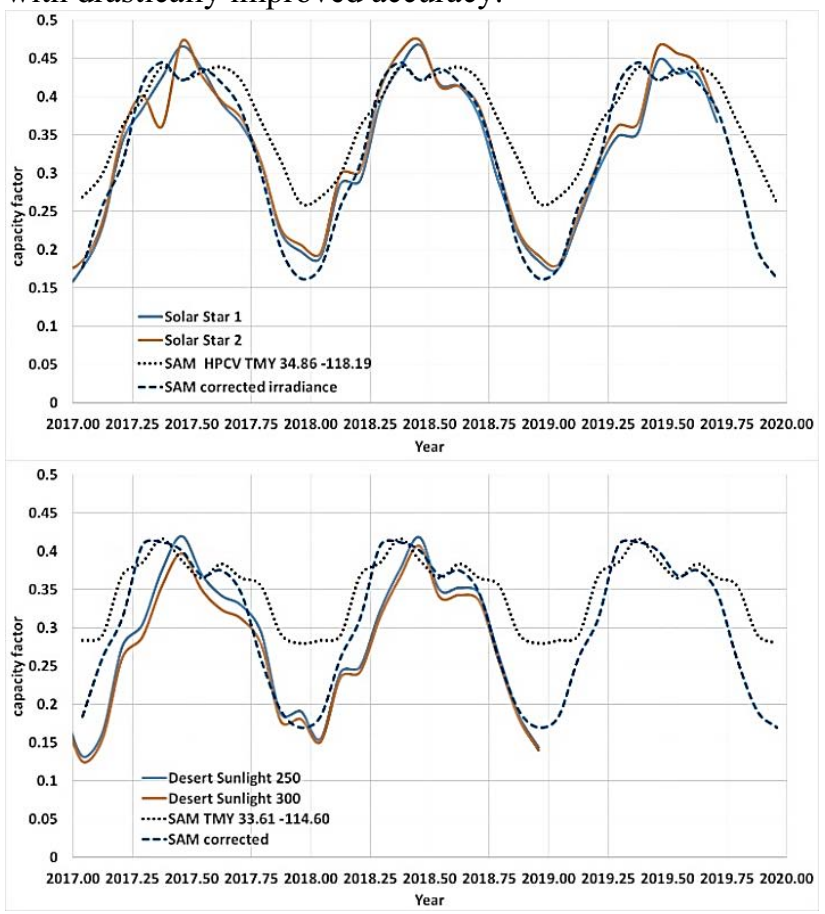

Fig. 4. Solar Star (top) and Desert Sunlight solar (bottom) solar energy facilities measured capacity factors over the last 3 years and computed capacity factors for the typical year with and without corrections for input irradiance. 


\section{Discussion and Conclusions}

Real-world electricity production data has been shown for the two largest PV solar energy facilities in California (and the US). It is shown that after some issues upon start, these facilities are now delivering relatively high capacity factors. The latest capacity factors are $33.91 \%$ (for the more expensive Solar Star) and $27.59 \%$ (for the less expensive Desert Sunlight).

Over the year, the experimental capacity factors fluctuate from 0.467 to 0.185 in Solar Star 1 (ratio 2.524), and 0.474 to 0.192 in Solar Star 2 (ratio 2.468), while they fluctuate from 0.418 to 0.144 (ratio 2.909) in Desert Sunlight 1 , and 0.407 to 0.140 (ratio 2.909) in Desert Sunlight 2. The solar resource is about the same in the two locations.

The computational results with SAM are everything but accurate. However, the major issue is not the simple semi-empirical model, but the resource estimation, which dramatically underrates the seasonal differences. In the SAM weather database, the ratio in between the beam irradiance summer/winter for Solar Star is 1.844, while weather spark suggests a ratio for the average daily incident shortwave solar energy of about 2.8 , plus clearer skies during summer. The weather spark result is consistent with the electricity production data. The SAM weather file is not.

In the SAM weather database, the ratio in between the beam irradiance summer/winter for Desert Sunlight is 1.54 , while weather spark suggests a ratio for the average daily incident shortwave solar energy of about 2.6, plus clearer skies during summer. The weather spark result is consistent with the electricity production data. The SAM weather file is not.

While further tuning of the semi-empirical SAM model is needed before using this software to compute the performances of novel PV installations, the availability of accurate data for validation is a must.

As it happens with the wind resource that in the SAM supporting weather files is overrated, it also happens with the solar resource to be unreliable. In this case, it is the seasonal variability that is dramatically underrated.

Validation of accurate and reliable renewable energy software tools must be based on high frequency (every minute or less) accurate weather and plant data, with this latter both at the system, as well as the components, level.

Validation attempts such as comparison of computed annual electricity production with rumors in the press of electricity production for the same plants, such as [14], [15], [16], are by no way a proof that specific renewable energy tools can be used to design new renewable energy facilities properly computing their performances.

\section{References}

1. Almuhtady, A., Alshwawra, A., Alfaouri, M., Al-Kouz, W., \& Al-Hinti, I. (2019). Investigation of the trends of electricity demands in Jordan and its susceptibility to the ambient air temperature towards sustainable electricity generation. Energy, Sustainability, and Society, 9(1), 118.
2. Nader, N., W. Al-Kouz, S. Al-Dahidi. (2019). Assessment of Existing Photovoltaic System with Cooling and Cleaning System: Case Study at Al-Khobar City. Processes, 8(1), 9. doi:10.3390/pr8010009 16.

3. Al-Kouz, W., S. Al-Dahidi, B. Hammad, M. Al-Abed. (2019). Modeling and Analysis Framework for Investigating the Impact of Dust and Temperature on PV Systems' Performance and Optimum Cleaning Frequency. Applied Sciences, 9(7), 1397. doi: 10.3390/app9071397

4. Al-Bashir, A., M. Al-Dweri, A. Al-Ghandoor, B. Hammad, W. Al-Kouz. (2020). Analysis of Effects of Solar Irradiance, Cell Temperature and Wind Speed On Photovoltaic Systems Performance. International Journal of Energy Economics and Policy, 10(1), 353-359. doi:10.32479/ijeep.859

5. BP, Energy Economics, Statistical Review, Renewable Energy, Solar Energy (2019). www.bp.com/content/dam/bp/businesssites/en/global/corporate/pdfs/energyeconomics/statistical-review/bp-stats-review-2019-fullreport.pdf

6. California Energy Commission, California Solar Energy Statistics and Data (2019), www2.energy.ca.gov/almanac/renewables_data/solar/ind ex_cms.php

7. Energy Information Administration, Electricity Data Browser - Plant Level Data (2019). www.eia.gov/electricity/data/browser/

8. NREL, SAM (2019). sam.nrel.gov/

9. Gilman, P., SAM Photovoltaic Model Technical Reference, Technical Report NREL/TP-6A20-64102 (2015). www.nrel.gov/docs/fy15osti/64102.pdf

10. SANDIA, Sandia Inverter Model pvpmc.sandia.gov/modeling-steps/dc-to-acconversion/sandia-inverter-model/

11. King, D. et al, Performance Model for Grid-Connected Photovoltaic Inverters. Sandia National Laboratories. SAND2007-5036 infoserve.sandia.gov/sand_doc/2007/075036.pdf.

(2007).

12. Boretti, A., Cost and Production of Solar Thermal and Solar Photovoltaics Power Plants in the United States, Renewable Energy Focus. 26:93-99 (2018). doi.org/10.1016/j.ref.2018.07.002

13. weather spark, The Typical Weather Anywhere on Earth (2019). weatherspark.com/

14. NREL, SAM validation, sam.nrel.gov/concentrating-solar-power/cspvalidation.html

15. NREL, System Advisor Model (SAM) Case Study:Andasol-1 Aldeire, Spain (2013). /sam.nrel.gov/images/web_page_files/sam_case_csp_phy sical_trough_andasol-1_2013-1-15.pdf

16. NREL, System Advisor Model (SAM) Case Study: Gemasolar Fuentes De Andalucía, Spain (2013). sam.nrel.gov/images/web_page_files/sam_case_csp_salt_ tower_gemasolar_2013-1-15.pdf 